rev.relac.int.estrateg.segur.13(2):73-95,2018

\title{
Cooperação na área de defesa na Unasul: um balanço do conselho de defesa sul-americano (CDS) e seus limites atuais*
}

\author{
Milton Carlos Bragatti** \\ Rubén Miranda Gonçalves***
}

\section{Resumo}

A área de defesa foi uma das que mais avançou no contexto da União das Nações Sul-americanas (Unasul); porém, há muitos desafios e problemas para mais cooperação nessa área. Embora, nos primeiros anos, o Conselho de Defesa Sul-americano (CDS) e a Unasul tenham obtido êxitos, também tiveram sinais de es-

* O presente artigo faz parte do projeto de pesquisa DER2017-DER201783436-C2-1-R, concedido pelo Competitividade concedido pelo Ministério de Economia, Indústria e Competitividade de Espanha.

** Mestrado em International Communication Arts, no New York Institute of Technology, Estados Unidos. Mestre em Integração Regional Contemporânea, na Universidad Federal de la Integración Latinoamericana (Brasil). Estudos de Pós-graduação / Integração Regional, Relações Interamericanas e Cooperação Sul-Sul, CLACSO (Argentina). Graduado em Ciências Sociais, pela Universidade de São Paulo (Brasil).miltonbragatti@yahoo.com

*** Professor no Mestrado em Segurança, Paz e Conflitos Internacionais da Universidad de Santiago de Compostela. Licenciado em Direito, com Grau, sobressaliente. Mestre em Direito das Administrações e Instituições Públicas. Doutorando em Direito Administrativo na Universidade de Santiago de Compostela. Membro colaborador do projeto "La respuesta en un Estado de Derecho a los retos de seguridad: fortalecimento democrático, derechos fundamentales y deberes de la ciudadanía", con referencia DER2017-DER2017-83436C2-1-R Ruben.miranda@usc.es 
tancamento. O objetivo deste artigo é fazer um balanço da cooperação na Defesa na América do Sul dentro do CDS. Nesse sentido, pretende-se compreender o processo de criação do CDS e a complexidade e perspectivas que permeiam a área da Defesa na América do Sul, suas conquistas e limites atuais.

Palavras-chave: Conselho de Defesa; Cooperação Militar; Integração regional; Unasul.

\title{
Cooperación en el área de defensa en la Unasur: un balance del Consejo de Defensa Sudamericano (CDS) y sus límites
}

\section{Resumen}

El área de defensa fue una de las que más avanzó en el contexto de Unasur; sin embargo, hay muchos desafíos y problemas para más cooperación en esa área. Si bien en los primeros años el Consejo de Defensa Sudamericano (CDS) y la Unasur obtuvieron éxitos, hay signos de estancamiento. El objetivo de este artículo es hacer un balance de la cooperación en Defensa en América del Sur dentro del CDS. Así, se busca comprender el proceso de creación del CDS y la complejidad y perspectivas que permean el área de la Defensa en América del Sur, sus logros y sus límites actuales.

Palabras clave: consejo de defensa; cooperación militar; integración regional; Unasur.

\section{Cooperation in the Defence Area in UNASUR: Assessment of the South American Defence Council (CDS) and its Limits}

\begin{abstract}
Defence was one of the areas with most progress in the context of UNASUR; however, there are many challenges and problems for further cooperation in this regard. While the South American Defence Council (CDS) and UNASUR achieved success in the first years, there are signs of stagnation. The objective of this article is to take stock of cooperation in defence in South America within the CDS. Thus, we seek to understand the process of creating the CDS and the complexity and perspectives that permeate the defence area in South America, its achievements and current limits.
\end{abstract}

Keywords: defence council; military cooperation; regional integration; UNASUR. 


\section{Introdução}

A inauguração de seu moderno edifício em Quito, no Equador, marcou, em 2015, os oito anos de existência da União das Nações Sul-Americanas (Unasul). Além da nova sede, foi inaugurada, no mesmo ano, a Escola Sul-Americana de Defesa, a Esude, com a finalidade de formar quadros militares e de funcionários de Defesa com uma visão compartilhada no tema no continente.

Desde sua fundação, a Unasul obteve sucessos no gerenciamento e controle de várias crises políticas, como o desmantelamento da tentativa de golpe no Equador, em 2010; a discussão sobre a instalação e uso de bases militares colombianas pelos Estados Unidos em 2009, e a mediação da crise entre oposição e governo na Venezuela em 2014. Estas, entre outras situações, mostram que a atuação da Unasul poderia representar um "subsistema político internacional diferenciado" nas Américas (Peña, 2009).

No entanto, se existem motivos para celebrar, há também elementos para se preocupar com uma visível "inflexão" no alcance da entidade: o recente apelo da Bolívia à Corte de Haia - e não à Unasul - para resolver a questão da saída ao mar, no seu litígio de fronteira com o Chile; a negociação entre as Forças Armadas Revolucionárias da Colômbia (Farc) e o governo da Colômbia, onde até atores extrarregionais assumiram o protagonismo; e acordos bilaterais com países extrarregionais - notadamente Rússia e China - em defesa. Esses eventos enfatizam o momento delicado que o CDS-Unasul atravessam para se firmarem e desenvolverem seu potencial de entidade primordial na resolução desses assuntos.

O objetivo deste artigo é fazer um breve balanço das ações do CDS, dos problemas, da complexidade e das perspectivas que permeiam a área da Defesa na Unasul. Apresentam-se, neste capítulo, os fundamentos principais da cooperação em defesa sul-americana e desenvolvimento das iniciativas e projetos fundamentais no âmbito do CDS da Unasul. Apresenta-se o processo de criação da Unasul e do CDS, e sua implicação para a cooperação em defesa sul-americana. E, finalmente, apresenta-se um breve sumário dos Planos de Ação do CDS e suas conquistas e limitações (primeiro eixo: políticas de defesa; segundo eixo: cooperação militar, ações humanitárias e operações de paz; terceiro eixo: indústria e tecnologia de defesa; quarto eixo: formação e capacitação), além do trabalho realizado pelo Centro de Estudos Estratégicos de Defesa (Ceed) e a criação da Esude. Finalmente, apontam-se os limites, as dificuldades e as perspectivas para a cooperação em defesa na América do Sul. 


\section{O CDS e a defesa na Unasul: da iniciativa promissora ao risco de inflexão}

A área de Defesa foi uma das que mais avançaram no contexto da Unasul, e este é um dos aspectos que a diferenciam de outros processos de regionalismo que desenvolveram mais outras áreas, como o comércio e a defesa da democracia. Além dos trabalhos realizados pelo Ceed, em Buenos Aires, a criação e inauguração da Esude, em Quito, são várias as ações que reforçam e estimulam a cooperação em defesa no continente, como a definição de Planos de Ação na área de segurança e defesa, a construção de metodologia comum de medição dos gastos em defesa e intercâmbios em formação e capacitação militar (Fuccille, 2014).

No entanto, a Unasul e, em especial, o CDS parecem atravessar um momento de inflexão, como a decisão da Bolívia de apelar para a Corte de Haia - e não à Unasul - para a resolução de seu pleito de saída para o mar e tensão com o Chile; a entrada de outros atores e instituições na mediação das tensões e conflitos entre a oposição e o governo venezuelano, e as negociações de paz entre as Farc e o governo colombiano, em que a Unasul não tem tido papel principal. Além disso, no âmbito da indústria de defesa, nos últimos anos, há uma profusão de acordos bilaterais entre países sul-americanos com parceiros extrarregionais, como a China e a Rússia, além do Irã, na área de equipamentos militares. Isso tudo num contexto de reconfiguração geopolítica no continente, com o restabelecimento das relações entre os Estados Unidos e Cuba, além de vários pleitos eleitorais na região que apontam para uma mudança de ventos nas iniciativas de integração e cooperação sul-americana.

Propomo-nos a fazer um breve levantamento dos avanços institucionais da Unasul e do CDS, e realizar um balanço resumido de seu desenvolvimento, num contexto de reorientação política de vários países no continente, notadamente Brasil e Argentina, além dos contextos globais de câmbios político-institucionais.

O CDS baseia-se no respeito à soberania e à não intervenção, e seus objetivos são o de consolidar a América do Sul como uma zona de paz, livre de armas nucleares e de destruição em massa; construir uma "identidade" $^{\prime \prime}$ sul-americana de defesa; reforçar a cooperação regional em matéria de defesa e aumentar a defesa soberana dos recursos naturais da região. A Unasul é configurada como um mecanismo relativamente flexível e eficaz para a gestão de crises e, em alguns casos, para a prevenção de conflitos, em parte como uma alternativa para a Organização dos Estados Americanos - OEA (Sanahuja e Verdes-Montenegro, 2014).

Entre outros fatores, o CDS surgiu de esforços para buscar estabelecer um foro de consultas e diálogo na área de Defesa na América do Sul e desen- 
volver medidas de confiança mútua, como, por exemplo, uma metodologia comum para homogeneizar orçamentos de despesas e ativos de defesa de cada nação no continente e construir um projeto sobre a paz e cooperação de segurança na região. Embora existissem contatos e acordos entre os países nessa área durante anos, a arquitetura emergente que toma forma a partir de CDS representa a primeira institucionalização das questões de segurança em defesa no âmbito estritamente sul-americano (Saint-Pierre, 2012).

\section{Os quatro eixos de cooperação no Conselho de Defesa da Unasul: breve balanço (2008-2012)}

O Conselho de Defesa da Unasul é uma iniciativa relativamente nova, incipiente, que caminha a passos lentos e que ainda não passou por "provas de fogo", especialmente com relação a desafiar frontalmente os interesses de potências extrarregionais (Fuccille, 2014). Segundo Fuccille (2014), "só foi possível erigir uma estrutura como o CDS pela opção de não-confrontação aberta com Washington". Ainda conforme o mesmo autor, o CDS é um processo até agora de certa forma "consentido" pelos Estados Unidos. No entanto, o autor argumenta que:

\section{[...] importantes avanços têm sido} registrados, como a definição de Planos de Ação comuns na temática de segurança e defesa, o estabelecimento de medidas de confiança mútua, a criação do Centro de Estu- dos Estratégicos de Defesa (CEED) na cidade de Buenos Aires, a instituição da Escola Sul-Americana de Defesa (Esude) para altos estudos, a construção de uma metodologia comum de medição dos gastos em defesa, um importante intercâmbio em matéria de formação e capacitação militar, entre outros pontos igualmente meritórios. (Fuccille, 2014)

Para desenvolver suas atividades de cooperação em Defesa, o CDS estabeleceu quatro eixos principais de atuação no continente: (1) política de defesa, (2) cooperação militar, ações humanitárias e operações de paz, (3) indústria e tecnologia de defesa, e (4) formação e capacitação. Nos seus cinco primeiros anos, é possível realizar um balanço relativamente positivo das atividades da entidade, apesar de críticas tanto de acadêmicos como de autoridades políticas e militares com o que é percebido como vagarosidade na implantação de suas resoluções.

\section{Primeiro eixo: políticas de Defesa}

O primeiro eixo, políticas de Defesa, é considerado o principal nas três primeiras edições do Plano de Ação do CDS. Nesse eixo, a Unasul e o CDS procuram desempenhar um papel na afirmação de uma visão estratégica comum, de uma abordagem regional para a segurança, e uma identidade sul-americana.

Enquanto ainda há um debate e certa discordância entre as várias nações sobre o que se configura ameaça, prio- 
ridades e visões estratégicas, na visão de Sanahuja e Verdes-Montenegro (2014), pode-se dizer que há um processo de regionalização a partir de um quadro comum e uma instância de comunicação, socialização e aprendizagem levadas a cabo pelo CDS. Alguns temas são constantes, segundo esses autores, demonstrando a sua priorização pelo CDS: é o caso do grupo de trabalho para a transparência do inventário militar dos países da região, a criação de uma plataforma virtual de comunicação (desde 2012) e do grupo de trabalho para o estabelecimento de uma política regional para ameaças cibernéticas e informáticas, a proteção e defesa dos recursos naturais e a discussão conceitual de ameaças comuns a todos os Estados sul-americanos.

A implantação e o trabalho desenvolvidos pelo Ceed no âmbito do CDS visa contribuir para a definição de abordagens estratégicas na região e para a articulação de uma identidade de defesa sul-americana: dos quatro estudos publicados pelo Ceed até 2012, dois abordaram a conceituação de segurança e defesa na região, observando a diversidade de visões e estruturas institucionais existentes entre os doze países, segundo Sanahuja e Verdes-Montenegro.

O CDS visa construir um sistema de defesa cooperativa; para diferenciar claramente a segurança pública e a defesa nacional, o alcance das forças armadas é limitado para a resposta de ameaças externas que colocariam em perigo a integridade territorial e a so- berania nacional; portanto, os países que participam do Conselho buscariam não recorrer às Forças Armadas para responder a ameaças internas e ou transnacionais (Sanahuja e Verdes-Montenegro, 2014).

Um estudo elaborado pelo Ceed abordou também a proteção dos recursos naturais e da biodiversidade da região, considerada "estratégica", em que uma das principais ameaças na região, sendo rica em recursos, é relacionada, segundo Sanahuja e Verdes-Montenegro, a tentativas de controle estrangeiro sobre petróleo, água e recursos minerais e agroalimentares; portanto, poderiam estar sujeitos a conflitos. Essa "geopolítica de recursos naturais" sugere que a Unasul procure construir um espaço geopolítico integrado que garanta o acesso e controle de seus membros de potenciais ameaças extrarregionais (Sanahuja e Verdes-Montenegro, 2014).

A publicação do registro sul-americano de gastos de defesa abre um novo caminho de institucionalização na medida em que os países-membros reúnem-se e têm noção clara de seus orçamentos e expectativas do relatório anual dos seus custos de defesa (Fuccille, 2014; Sanahuja e Verdes-Montenegro, 2014; Saint-Pierre e Montoya, 2014).

\section{Segundo eixo: manutenção da paz (cooperação militar, ações humanitárias e operações de paz)}

O segundo eixo dos Planos de Ação, sobre cooperação militar, ações hu- 
manitárias e operações de paz, busca aliar as experiências regionais de operações combinadas e conjuntas através de treinamentos comuns; além disso, busca uma forma de atuação conjunta e de uso compartilhado dos mecanismos já existentes, na visão de autores como Rezende (2013) e Sanahuja e Verdes-Montenegro (2014). Através dos exercícios interaliados Unasul I, Unasul II e Unasul III, pretende-se, através do treinamento conjunto, diminuir as discrepâncias das doutrinas militares diferentes das FFAA sul-americanas (Rezende, 2013).

A experiência compartilhada entre várias nações sul-americanas em suas experiências no envio de tropas para missões de paz para a Organização das Nações Unidas (ONU) foi aproveitada como fator potencializador de troca de informações e medidas de confiança entre os países da região.

A participação da América do Sul nas operações de paz não é recente: desde a fundação da ONU, Argentina, Brasil, Chile e Uruguai têm enviado observadores militares para missões da organização em várias partes do mundo. No entanto, a partir da década de 1990 (e especialmente depois dos anos 2000), essa participação atingiu níveis inéditos, constando como região de maior contribuição nas missões de paz da ONU. Esses países sul-americanos identificaram que a participação em missões de paz da ONU é uma parte integrante do compromisso com a manutenção da paz e segurança internacional (Souza Neto, 2013).
A decisão de participar em missões da paz da ONU tem relação, entre outros fatores, especialmente com a política externa de cada país. Segundo Aguilar (2011):

A decisão de integrar forças de paz é governamental, é vontade política, motivada por diversas razões que vão desde a ajuda humanitária, desprovida de qualquer outra intenção, até a utilização dessas missões como forma de aumentar sua inserção no meio internacional. Pode ocorrer, também, por interesses particulares em relação às organizações [...], ou ainda, em decorrência de cumprimento de obrigações geradas por tratados. Afinidades com o país ou países em conflito também são importantes fatores que pesam na decisão [...]. Há, ainda, a questão da solidariedade com países da região. As chamadas parcerias estratégicas também são fatores que pesam na decisão [...] Um possível aumento de prestígio, de projeção do país no sistema internacional ou a busca da liderança regional [...] podem balizar uma maior ou menor presença nessas missões. (p. 109-110)

Ao longo da história, os países sul-americanos tiveram diferentes motivações para atuarem nas missões de paz. Os "ABC + U" - ou seja, os estados do Cone Sul: Argentina, Brasil, Uruguai e, em menor grau, Chile - são os mais comprometidos com as operações de paz da ONU, com os estados andinos começando a seguir esses passos, segundo Souza Neto (2013). 
Aguilar (2011) ressalta algumas diferenças importantes entre os países do Cone Sul com relação às missões de paz da ONU:

Argentina, Brasil e Uruguai são os países sul-americanos com maior tradição de participação em operações de paz. Chile, Paraguai, Peru e Equador incrementaram suas presenças a partir da década de 1990 e demonstram a intenção de permanecerem mais atuantes nesses empreendimentos. A Colômbia esteve presente nas missões clássicas, mas, em decorrência do grave problema de segurança interna, teve uma tímida presença nas últimas décadas. A Venezuela não participa de nenhuma operação atualmente, uma vez que suas políticas externas e de defesa não priorizam as missões de paz. (p. 108)

Esses países deixaram de lado as resistências do passado, que associavam de certa forma missões internacionais com intervenções militares realizadas pelos Estados Unidos nas décadas anteriores (Kenkel, 2013). Essa percepção deu lugar a uma ideia mais cooperativa especialmente porque esses países começaram a perceber que essas missões ofereciam diversas vantagens para a promoção de suas políticas e posições no âmbito internacional, além de contribuição em suas questões domésticas. Oportunidades como aumentar o controle dos militares por parte de autoridades civis, manter mais militares na arena internacional para treiná-los em tempo real em situações de combate e contribuir com os princípios da diplomacia preventiva e resolução pacífica de conflitos estavam presentes no campo. Kenkel (2013) e Vales (2013) acreditam que o processo de democratização nas décadas de 1980 e 1990, o fim de vários conflitos e o crescente processo de integração regional mudaram algumas das concepções locais sobre o princípio da soberania do Estado, além de terem gerado maior compromisso com o multilateralismo.
O fim dos regimes militares e a re- democratização conduziram a um maior controle civil das Forças Ar- madas e ao desenvolvimento das chamadas medidas de confiança mútua (MCM) com a cooperação, substituindo a rivalidade entre os países que, no caso do Cone Sul, foram favorecidas pela própria constituição do Mercosul. (Aguilar, 2008, p. 1)

Atualmente, os países sul-americanos buscam se organizar em bloco regional e compartilham, assim, valores e políticas em vários aspectos. Instituições como o Mercado Comum do Sul (Mercosul), a Comunidade Andina e, mais recentemente, a Unasul são exemplos desses esforços. Com essas iniciativas, buscam promover a integração regional coordenando e organizando diversos campos, desde questões econômicas a temas relacionados às Forças Armadas (Vales, 2013, p. 2).

A participação em missões de paz da ONU tem sido um importante elemento de aproximação e cooperação em 
matéria de segurança e defesa para os países sul-americanos. Segundo Aguilar (2008), até 2011, os Estados da América do Sul tinham participado de 56 operações da ONU e, naquele ano, das 16 operações em curso, 12 contavam com a presença de países sul-americanos.

[...] a participação em mais operações e crescentes recursos humanos e materiais que lhes são atribuídos geraram mudanças institucionais e organizacionais, o que afetou os ministérios de Relações Exteriores, Defesa e as próprias forças militares e de segurança destes países. Neste sentido, a crescente participação em OMP [Operações de manutenção de paz] tornou necessária a criação de instituições específicas para o treinamento de tropas e unidades dedicadas à implantação organização, planejamento, logístico e desdobramento de pessoal. Este processo requereu, por sua vez, a incorporação de diretrizes de formação e nova doutrina para as forças armadas. (Llenderrozas, 2007, p. 30 , tradução nossa) $)^{1}$

Como exemplos de centro de treinamento de destaque na região pode-se citar o Centro Argentino de Formação Conjunta para Operações de Paz (CaecoPaz), estabelecido em 1995; o Centro Conjunto de Operações de Paz do Chile (Cecopac), iniciado em 2002, e o Centro Conjunto de Operações de Paz do Brasil (Ccopab), criado em $2010^{2}$. Os centros se especializaram para a formação necessária voltada às operações de paz, além de desenvolver intercâmbio entre instrutores e alunos no subcontinente (Aguilar, 2011; Llenderrozas, 2007).

A Missão de Estabilização das Nações Unidas no Haiti - Mission des Nations Unies pour la stabilisation en Haïti (Minustah) - é considerada a de maior nível em cooperação entre os países sul-americanos até o momento. A Minustah, fundada em 2004 e em funcionamento até os dias atuais, serviu como palco para níveis sem precedentes de coordenação e cooperação entre os Estados da América do Sul. Foi a primeira missão em que países sul-americanos responderam ativamente com efetivos militares e civis em uma crise de país da região. Além de países da América do Sul, contingentes de países da América Central somaram-se, o que criou uma identidade latino-americana na operação (Llenderrozas, 2007; Hirst, 2007).

Souza Neto (2013) lembra que, em 1996, os estados-membro do Mercosul decidiram criar um fórum para a coordenação entre os seus ministros de Relações Exteriores a fim de promover posições comuns em institui-

1 [...] la creciente participación en OMP volvió necesaria la creación de instituciones específicas para la formación de los efectivos y dependencias dedicadas a la organización, planificación, logística y despliegue de personal. Este proceso requirió, a su vez, la incorporación de pautas de entrenamiento y doctrina novedosas para las fuerzas armadas.

2 Originado do anterior Centro de Instrução de Operações de Paz (cıoPaz), criado em 2005. 
ções internacionais, que aconteceu principalmente no Conselho de Segurança da ONU. A participação desses países na Minustah também teria contribuído para aproximar os países contribuintes com tropas (TCCS): Argentina, Brasil, Chile, Peru e Uruguai foram membros ativos do Grupo de Amigos do Haiti da ONU e convidados a participarem de reuniões do Conselho de Segurança para discutir a situação no Haiti, bem como coordenarem suas posições a respeito da renovação de mandato e de alterações nas suas prioridades da missão.

Em decorrência da não participação desses países na história de colonização e intervenção do Haiti, ao contrário do caso da França e da Inglaterra, esses Estados conseguiram uma forma diferente de atuação com seu contingente militar, a qual buscou descaracterizar a imagem de invasão, de ocupação, tentando assim uma aproximação com a população local, por meio de atividades de caráter civil, como as da Ação Cívico Social - Aciso $^{3}$ (Souza Neto, 2010).

A cooperação sul-americana no Haiti foi beneficiada por alguns fatores, como as iniciativas anteriores de cooperação; a hierarquia militar sem diferenças; a cultura e a proximidade do idioma, e o intercâmbio de oficiais para a realização de cursos militares entre os diferentes centros presentes na região, o que permite uma padronização no conhecimento sobre operações de paz (Souza Neto, 2010).

A experiência acumulada pelas forças armadas e policiais, o intercâmbio de conhecimento e de pessoal, os exercícios conjuntos direcionados para esse tipo de operação realizados pelos exércitos, especialmente os do Cone Sul, e as iniciativas de coordenação entre governos são importantes para a consecução e o sucesso das iniciativas voltadas para a resolução de conflitos. São importantes, sobretudo, para o fomento da confiança mútua com reflexos na manutenção da paz e da segurança regional. (Aguilar, 2011, p. 112)

Segundo Souza Neto (2010, p. 50-51), "O envolvimento na Minustah proporcionou o estabelecimento de laços entre o Haiti e os países da região, diminuindo o isolamento em que o Haiti se encontrava e (re)integrando o país à comunidade latino-americana".

A Missão gerou ainda ganhos em cooperação em segurança e defesa na América do Sul. Dentre as iniciativas regionais de influência pela Minustah, pode-se destacar o mecanismo 2x9, bem como a Associação Latino-Americana de Centros de Treinamento para Operações de Paz (Alcopaz), a Força de Paz Combinada Cruz del Sur e o CDS, no âmbito da Unasul -

3 Caracterizada como uma operação de contato com a comunidade, por exemplo, atendimento médico, distribuição de alimentos, atividades culturais, distribuição de água, palestras educativas, etc. 
como esforços da cooperação política e de segurança e do desejo de plurilateralização das ações e envolvimento de manutenção da paz (Souza Neto, 2010; Kenkel, 2013).

A Alcopaz é uma associação de centros de formação de manutenção de paz, uma iniciativa apresentada pela Argentina, com o objetivo de promover a eficiência e a eficácia no envolvimento da América Latina nas operações de paz. A associação foi criada em agosto de 2008 e seus membros atuais incluem Argentina, Brasil, Chile, Colômbia, Paraguai, Equador, Guatemala, Peru e Uruguai. Um dos principais efeitos da associação é tentar apresentar uma voz comum na Associação Internacional de Manutenção da Paz de Centros de Treinamento (laptc), bem como servir como fórum de compartilhamento de lições aprendidas, intercâmbio entre os centros, iniciativas de pesquisa acadêmica sobre as questões relacionadas com as operações de paz e promover intercâmbio de conhecimento entre os militares, a polícia e os componentes civis, com o objetivo de incentivar a padronização de treinamento e procedimentos para seguir as diretrizes da ONU (Souza Neto, 2013).

No âmbito do CDS da Unasul, os objetivos que se relacionam com a cooperação de paz internacional incluem: alcançar uma posição regional comum em instituições multilaterais; promover a interoperabilidade das forças armadas; aumentar a participação regional com base em uma doutrina comum e consolidar o compromisso de participar de missões humanitárias (Souza Neto, 2010).

O primeiro seminário realizado do CDS para discutir questões de missõs de paz foi realizado em Montevidéu, em setembro de 2010, onde os participantes decidiram criar um mecanismo para coordenar todas as áreas relacionadas com a participação nas operações, com vistas a evitar a duplicação de esforços e aumentar as capacidades dos estados-membros a participarem de tais missões. Esses esforços coordenados envolveram exercícios de manutenção de paz conjuntos (que já existiam antes da Minustah), seminários e intercâmbio entre os centros de formação de operações de paz na região.

A Força de Paz Combinada Cruz del Sur é uma iniciativa bilateral, formada por Argentina e Chile. O Acordo de força de paz combinada foi firmado em 2005. Nele o treinamento e o preparo ficariam a cargo do Estado Maior Conjunto, que cuidaria da implementação operacional. Uma vez constituída, a força seria colocada em disposição da ONU, conforme o United Nations Stand-By Arrangement System (Unsas), podendo ser deslocada com o pedido da ONU e a aprovação dos dois países. Vendo uma iniciativa como essa, pode-se constatar como uma operação de paz como a Minustah, com seus níveis de cooperação e interação, pode gerar uma medida de construção de confiança mútua e de superação de rivalidades e desconfian- 
ças entre países, tendo em vista que Argentina e Chile possuem um histórico de disputas territoriais na década de 1980 (Souza Neto, 2010, p. 46).

\section{Terceiro eixo: indústria e tecnologia de defesa}

A cooperação no domínio da indústria e tecnologias de defesa é uma questão importante para a Unasul e o CDS, a qual busca autonomia regional nessa área, a partir da tentativa de redução da dependência dos fornecedores tradicionais na Europa e nos Estados Unidos. Um dos objetivos seria desenvolver uma indústria regional de Defesa que, para assegurar seu desenvolvimento, tem a necessidade de uma escala internacional e tecnologia próprias, ou seja, um país sozinho teria dificuldade para desenvolver tal tecnologia; assim, esta torna-se possível através da cooperação regional.

O Brasil é, por sua dimensão e pela força de sua indústria de armamentos, o país com mais capacidades e interesse em desenvolver essa dimensão da Unasul. No Plano de Ação 2010-2011, é o eixo que registrou mais atividades (Rezende, 2013; Sanahuja e Verdes-Montenegro, 2014).

O CDS realizou uma avaliação de indústrias e tecnologias na região e procurou manter um sistema integrado de informações, além de promover seminários e eventos sobre os temas de segurança, tecnologia industrial básica e de defesa para incentivar a cooperação e o intercâmbio de expe- riências (Sanahuja e Verdes-Montenegro, 2014).

Além disso, como ressalta Rezende (2013), dois outros projetos importantes são: o desenvolvimento e produção de uma aeronave de treinamento básico ("Unasul I"), liderado por Brasil e Argentina, e um sistema de veículos aéreos não tripulados (VANTS), liderado pelo Brasil — além da participação de empresas do Chile e da Argentina no projeto da aeronave de transporte militar KC-390 (Rezende, 2013; Sanahuja e Verdes-Montenegro, 2014).

Entre os países sul-americanos, apenas a Argentina, o Brasil e o Chile desenvolveram uma incipiente indústria de defesa nacional. Como observa Tamires Souza (2015), “o Brasil pode ser considerado como o maior produtor sul-americano, devido, principalmente, à base industrial criada durante a ditadura militar" (p. 139).

Porém, Souza (2015) ressalta que, com o fim da Guerra Fria, o cenário favorável para esses países sofreu mudanças como a elevação da competição entre indústrias de defesa internacionais e, citando Vilela, diz que "a redução da demanda de produtos militares, que somada ao decrescimento 'das tarifas alfandegárias resultante das pressões neoliberais e à falta de incentivo dos governos, levou muitas indústrias de defesa sul-americanas à falência ou a diversificarem suas produções'" (Vilela, 2009 citado por Souza, 2015, p. 139). 
No caso brasileiro, Peterson Silva (2011) observa que, somente com parcerias internacionais e iniciativas de cooperação regional, como a ensejada pelo CDS, o país poderá desenvolver autonomamente sua indústria de Defesa:

A exemplo de outros países, a busca por uma autonomia plenamente nacional (brasileira) em indústria de defesa dificilmente se realizará. Nessa direção, as parcerias e as relações com grandes conglomerados internacionais do setor serão cada vez mais importantes para a indústria de defesa brasileira, principalmente no que se refere às recentes discussões em torno do Conselho de Defesa Sul-americano da Unasul ou em programas como o cargueiro KC-390 da Embraer. Ademais, dificilmente as empresas brasileiras do setor terão êxito no longo prazo sem enfrentar o competitivo, concentrado e politizado mercado internacional de defesa. Nesse certame, as variáveis tecnológicas, militares, comerciais, industriais, diplomáticas e militares terão, necessariamente, que ser coordenadas entre diferentes agências e ministérios. (Silva, 2011, p. 238)

\section{Quarto eixo: formação e capacitação}

O cDS tem desenvolvido várias instâncias na área de formação e capacitação: além do Ceed, em Buenos Aires, foi criada e inaugurada a Esude, com sede em Quito.
O Ceed é uma instância de produção de estudos estratégicos, um think tank, que tem como missão a geração de conhecimento e a difusão de um pensamento estratégico sul-americano em termos de defesa e segurança regional e internacional, sempre por iniciativa do CDS (Sanahuja e Verdes-Montenegro, 2014). O objetivo da Esude é promover e difundir consensos nas questões estratégicas através do diálogo.

O novo centro de estudos da Esude foi inaugurado em 2015 e começa a funcionar na cidade de Quito, capital do Equador, cidade sede da Unasul, chefiado pelo brasileiro Antônio Jorge Ramalho, assessor especial do Ministério da Defesa e professor de Relações Internacionais da Universidade de Brasília (UnB).

Outras ações reforçam e estimulam a cooperação em defesa no continente, como a definição de Planos de Ação na área de segurança e defesa, a construção de uma metodologia comum de medição dos gastos militares em defesa e os intercâmbios em formação e capacitação militar (Fuccille, 2014).

A inauguração e a implementação da Esude, apesar de ainda não explicitar suas características e como será seu funcionamento e, como aponta Rezende (2013), de mostrar que as iniciativas nesse sentido vêm caminhando, consolidando a experiência dos Cursos Avançados de Defesa Sul-Americana (CAD-SUL), realizados pela ESG em anos anteriores. Ainda que sejam poucas e 
a maior parte delas bancadas financeiramente pelo Brasil, essas iniciativas de treinamento conjunto têm crescido (Rezende, 2013).

Com formato descentralizado, a Esude é um centro de altos estudos, responsável pela articulação das diversas iniciativas dos países-membros do CDS para a capacitação de civis e militares nas áreas de Defesa e Segurança Regional. Ainda nesse sentido, o Ceed foi criado em março de 2009, como órgão subordinado ao CDS, e tem como missão contribuir para a geração e propagação de um conhecimento estratégico sul-americano voltado à defesa e à segurança regional e internacional, contribuindo e desenvolvendo uma visão compartilhada por todos os países-membros da Unasul (CDS, 2010).

De acordo com Frenkel (2016), a Esude contemplou princípios de gradualismo e flexibilidade, num desenho institucional descentralizado composto de uma rede de instituições nacionais, cursos e disciplinas variadas, com uma proposta acadêmica que pode ser individual para cada estado-membro ou em conjunto com outros países. O autor ressalta:

[...] a criação da Esude tem forte apoio nas iniciativas desenvolvidas prévia e diretamente ligadas à formação de civis e militares, comandadas principalmente por alguns países promotores: desde 2012, o Brasil realiza o Curso Avançado de Defesa para civis e militares, e a Argentina organiza o Curso de Formação Sul-americano de Defesa Civil. O Equador, por sua vez, planeja, desde 2014, o Curso Sul-americano de Defesa e Pensamento Estratégico. (Frenkel, 2016, p. 45, tradução nossa) ${ }^{4}$

O Ceed foi pensado como um órgão de produção acadêmica para assessorar e prover as informações necessárias ao CDS. Sua sede fica em Buenos Aires, e coube à Argentina ceder o espaço físico - e percebe-se que é esse país que vem tendo maior número de iniciativas para o desenvolvimento do Ceed, como apontam Rezende (2013) e Sanahuja e Verdes-Montenegro (2014). Um dos grandes desafios a que o Ceed se propõe, e ainda não resolveu, é conceitual, sobre o papel e a função das Forças Armadas em nossa região. A relação entre política interna e forças armadas deve ser clara. Nesse sentido, as diferenças doutrinárias das FFAA sul-americanas atrapalham a cooperação em defesa, ao criarem complicadores, o que restringe a cooperação (Rezende, 2013).

4 [...] la creación de la Esude tiene un fuerte sustento en el desarrollo previo de iniciativas directamente vinculadas con la formación de civiles y militares, comandadas en su mayoría por los países promotores: Desde 2012, Brasil realiza el "Curso Avanzado de Defensa para civiles y militares" y Argentina organiza el "Curso Sudamericano de Formación de Civiles en Defensa". Ecuador, por su parte, viene planificando desde 2014 la realización del "Primer Curso Suramericano de Defensa y Pensamiento Estratégico". 


\section{Considerações finais: limites, dificuldades e perspectivas para a cooperação em Defesa na América do Sul}

O Conselho de Defesa da Unasul, em poucos anos de existência, alcançou progresso significativo no diálogo político. A institucionalização de um processo de construção regional de cooperação em Defesa contribui para a confiança entre os Estados, favorecendo a consolidação da região como zona de paz.

A construção de medidas e instrumentos de confiança e de cooperação contribuem para mudar ou, ao menos, diminuir a percepção de rivalidade, tensão, desconfianças e até mesmo a competição entre os Estados. Nesse sentido, o intergovernamentalismo da Unasul tem sido conveniente para construir a confiança entre os Estados e o desenvolvimento institucional da organização, além de favorecer a consolidação de uma zona de paz, denotando um pragmatismo entre Estados relutantes em ceder soberania na tomada de decisões sobre políticas em organismos comuns. No entanto, esse intergovernamentalismo também pode ser responsável pelos limites e dificuldades enfrentados pelo CDS na formulação e implantação de seus projetos e diretrizes. Num recente balanço sobre o papel do CDS, Fuccille argumenta que

[...] a despeito de disputas (pontuais ou não) entre os diferentes Estados sul-americanos no proces- so de construção e condução da integração regional, parece haver um fio condutor comum (excetuando a Colômbia) com respeito à temática segurança e defesa, que é a aspiração por parte das lideranças políticas do fim da heteronomia e ingerência norte-americana na região. Neste particular, a América do Sul, concretamente, parece vivenciar uma nova realidade, com o florescimento, inclusive, de novas institucionalidades, como o ConseIho de Defesa Sul-Americano e outros mecanismos. (Fuccille, 2015, p. 115)

A consolidação do conceito de região sul-americana e o processo de construção da Unasul têm criado configurações no tabuleiro geopolítico da região, abrindo uma disputa na resolução de questões que eram até então discutidas somente no âmbito da OEA, com potencial impacto na geopolítica hemisférica e global.

No entanto, a Unasul e, em especial, o CDS parecem atravessar um momento de inflexão, com a entrada de outros atores e instituições na mediação das tensões e conflitos na região, em que a Unasul não tem tido papel principal. No âmbito da indústria de defesa, nos últimos anos, há uma profusão de acordos bilaterais entre países sul-americanos com parceiros extrarregionais, como a China e a Rússia, além do Irã, na área de equipamentos militares - exemplo disso são os acordos da Colômbia com a Organização do Tratado do Atlântico Norte (Otan). 
Isso tudo num contexto de "shifting geopolitics", com o restabelecimento das relações entre os Estados Unidos e Cuba, além de vários pleitos eleitorais na região (com a eleição do novo presidente na Argentina e a vitória da oposição nas eleições congressuais na Venezuela, por exemplo), que podem sinalizar mudanças na orientação das iniciativas de integração e cooperação sul-americana, como, por exemplo, maior aproximação desses países aos Estados Unidos ou até mesmo esvaziamento de iniciativas como a Unasul. As mudanças em curso em países importantes para a consolidação da Unasul anunciam possibilidades de mudanças que podem ter efeito tanto na diminuição como num aumento da convergência política (como sugerem intentos por parte do governo brasileiro e argentino de aproximação com a Aliança do Pacífico, por exemplo), no que se refere a esses temas, ou reformulação da organização.

A regulamentação e as definições de atuação e a construção institucional do CDS são objeto de muitas controvérsias entre os países-membros - a começar pelas disputas iniciais entre as definições de "segurança" e "defesa", por exemplo, o enfrentamento de questões "intermésticas" (como o narcotráfico, o crime organizado etc.) ou disputas atuais e conflitos não resolvidos, como o pleito da Bolívia ao Chile por uma saída ao oceano e as crises diplomáticas cíclicas que envol- vem Colômbia, Equador e Venezuela. Ressalte-se, no entanto, que vários interesses - geopolíticos - nacionais de cada país integrante do CDS parecem ser contemplados com a adesão à entidade.

As percepções geopolíticas acompanham - e devem acompanhar — as mudanças nas conjunturas históricas. Nesse sentido, novos temas devem ser incluídos, inclusive no escopo da Unasul, em termos da segurança e defesa conjuntas: a conjugação de novos elementos ambientais de segurança às questões clássicas de ordem espacial - meio ambiente e questões climáticas; elementos e ameaças não apenas de ordem estatais, mas também não estatais, como, por exemplo, o narcotráfico e o terrorismo.

A criação do Conselho de Defesa da Unasul se configura como um instrumento importante de cooperação multilateral na defesa da América do Sul. O elemento inovador dessa iniciativa deve-se ao fato de que, até então, as iniciativas de integração entre países sul-americanos sempre se pautavam por acordos de caráter bilaterais, e não através de uma instituição regional que coordenasse os esforços de defesa na região. Na voz oficial de seus atores formuladores: "O Conselho de Defesa Sul-americano senta-se em um conjunto de consenso e algumas exclusões que permitem a realização da implantação de suas capacidades para 
ser um fórum político para o diálogo sobre questões de defesa" ${ }^{\prime \prime}$.

O discurso do Conselho também replica outras instituições regionais, como a OEA e o Mercosul, quanto à defesa dos princípios democráticos e da tradição de não interferência em assuntos internos de países da América do Sul. Porém, o CDS evita entrar de maneira mais enfática nos aspectos de segurança, mesmo sendo a América do Sul uma região fortemente afetada por atores e processos de segurança não estatais e transnacionais, tais como o tráfico de drogas, o crime organizado, o contrabando de armas e de pessoas, a presença de grupos insurgentes guerriIheiros ou paramilitares, a violência urbana, entre outros. Essa preocupação pode, em algumas instâncias, ser contraprodutiva, como vimos na tensão causada entre países andinos quando do assassinato do líder das Farc, Raul Reyes, por parte da Colômbia em solo equatoriano - ou seja, um problema doméstico, que se torna interméstico e com potencial espraiamento por toda a região. No entanto, para alguns autores, como Héctor Saint-Pierre, o foco estritamente militar em questões de defesa - ou "defesa dura" — do CDS tem fundamento. Isso evitaria que as forças armadas dos países da América do Sul fossem usadas para resolver problemas de segurança pública e pudessem se concentrar na defesa nacional (Saint-Pierre, 2011).

Além do foco na Defesa, por exemplo, a preocupação com os gastos militares e a transparência na apresentação destes, bem como a ausência de formulações sobre a segurança regional, o fato é que todos os países da região participam por diferentes motivos do Conselho. No entanto, a consolidação do Conselho de Defesa da Unasul enfrenta problemas, especialmente na esfera geopolítica regional do continente. Por outro lado, o CDS introduziu uma inovação geopolítica importante no hemisfério, consolidando a América do Sul como região diferenciada. Desde a formação do sistema hemisférico de instituições de segurança e defesa, após o fim da Segunda Guerra Mundial, era quase impossível pensar-se em alguma estrutura de tal natureza em que os Estados Unidos estivessem ausentes. O CDS é a primeira estrutura de defesa regional latino-americana em que os Estados Unidos não têm participação nem no seu processo de

5 Gonzalo García Pino, presidente do Grupo Constituição de Trabalho do CDS e subsecretário de Guerra do Ministério de Defesa do Chile: "En este sentido, tiene un conjunto de exclusiones, tales como, la definición de que se trata de un Consejo de Defensa y no de asuntos de seguridad. Asimismo, es un foro de encuentro político y no una alianza militar. Por lo mismo, es un espacio de diálogo que se construye a favor de un nuevo escenario y no va dirigido en contra de ningún país. Particularmente, no nace para oponerse a las políticas de defensa de Estados Unidos en la región" (CDS Unasul, 2009, p. 37). "Nesse sentido, tem um conjunto de exclusões, como a definição do que é um Conselho de Defesa e não de assuntos de segurança. É também um fórum de encontro político e não uma aliança militar. Portanto, é um espaço de diálogo que é construído para um novo contexto e não vai dirigido contra nenhum país. Particularmente, não nasceu para se opor a políticas de defesa dos Estados Unidos na região" (CDS Unasul, 2009, p. 37, tradução nossa). 
formulação, nem de execução de políticas. Porém, o processo que conduziu a tal resultado, de outro lado, não significou um processo de confrontação aberta entre os países sul-americanos e os Estados Unidos. "Só foi possível erigir uma estrutura como o CDS pela opção de não confrontação aberta com Washington", segundo Fuccille (2014), que argumenta que o CDS é um processo até agora de certa forma "consentido" pelos Estados Unidos.

No aspecto institucional, o autor ressalta que o CDS começou a desenvolver uma estrutura organizacional nos recentes anos: além do Ceed, em Buenos Aires, houve a criação e inauguração da Esude, com sede em Quito. Além disso, outras ações reforçam e estimulam a cooperação em defesa no continente, como a definição de Planos de Ação na área de segurança e defesa, a construção de uma metodologia comum de medição dos gastos militares em defesa e os intercâmbios em formação e capacitação militar (Fuccille, 2014).

O Ceed é uma instância de produção de estudos estratégicos, um think tank, que tem como missão a geração de conhecimento e difusão de um pensamento estratégico sul-americano em termos de defesa e segurança regional e internacional, sempre por iniciativa do CDS. O objetivo da Esude é promover e difundir consensos nas questões estratégicas através do diálogo. O novo centro de estudos da escola começa a funcionar na cidade de Quito, capital do Equador, cidade sede da Unasul, e é chefiado pelo brasileiro Antônio Jorge Ramalho, assessor especial do Ministério da Defesa e professor de Relações Internacionais da UnB.

No entanto, segundo Regueiro e Burzaga, não há indicações em políticas concretas que apontem para uma convergência entre os países e os vários processos existentes nesse espaço. Persistem diferenças entre os participantes com relação a temas centrais e a política básica dos países, e as prioridades com relação à integração não mudaram (Regueiro e Burzaga, 2012). Num balanço recente, Saint-Pierre e Montoya sustentam que há "um hiato entre as declarações políticas e as ações de cooperação em Defesa", além do fato de que não foram elaboradas e assimiladas novas doutrinas nas Forças Armadas da região, refletindo também que poucos países amadureceu o controle civil sobre os militares e também sobre a condução política da Defesa (Saint-Pierre e Montoya, 2014, p. 35).

Ainda de acordo com Saint-Pierre e Montoya, embora o CDS não tenha contemplado a criação de uma aliança militar, tal como propunha a Venezuela, a prioridade estratégica de integração das indústrias de defesa é uma forma adequada para consolidar confiança e, simultaneamente, alcançar a autonomia e autossuficiência da região (Saint-Pierre e Montoya, 2014). 


\section{Conclusão}

A realização de exercícios militares conjuntos, vários deles em andamento ou realizados periodicamente há anos, a divulgação consensual de despesas e de orçamento militar, a divulgação dos "livros brancos de defesa" de cada país e a integração e desenvolvimento de alguns projetos conjuntos na indústria de defesa (como a produção conjunta de aviões) são exemplos de que a cooperação em defesa no continente sul-americano tem potencial para se desenvolver de forma mais profunda, tendo no CDS sua agência catalizadora.

O Conselho de Defesa da Unasul, em seus poucos anos de existência, alcançou progresso significativo no diálogo político, na cooperação, no desenvolvimento institucional de segurança e na defesa. A institucionalização de um processo de construção regional contribui para a confiança entre os Estados, o que favorece a consolidação de uma zona de paz na região.

Na medida em que os avanços na segurança e na defesa têm ajudado a aumentar confiança entre os estados-membros, o Conselho de Defesa da Unasul abre caminho para estabelecer a região como uma área de paz genuína, cumprindo assim seus principais objetivos.

As várias mudanças e turbulências importantes na política de vários países da América do Sul a partir de 2015
- notadamente de ênfase conservadora-neoliberal, como a eleição de Maurício Macri, na Argentina, o processo de impeachment da presidente Dilma Roussef, no Brasil, além da evolução do processo de paz na Colômbia e de ganhos eleitorais importantes da oposição na Venezuela, entre outras - podem trazer também redefinições e reorientações potencialmente radicais nas estruturas e arranjos de regionalismo na região, especialmente na Unasul, que teve seu desenvolvimento sob a égide de vários governos de populares de esquerda.

No entanto, ressaltamos que a evolução da cooperação em Defesa na América do Sul demonstra que importantes ações e arranjos foram levados a cabo por governos de orientação "neoliberal", como na década de 1990 (auge do chamado "Consenso de Washington"), que serviram também como base inicial de vários desenvolvimentos e aprimoramentos vistos na conformação do CDS.

Nesse sentido, acreditamos que a cooperação em Defesa entre as várias nações da região deve seguir seu curso, mesmo com incertezas; assim como há riscos de "regressão" e diminuição dessa cooperação, não se pode descartar a possibilidade de aumentar, aprofundar-se e se desenvolver sob orientação de outras forças políticas, mesmo com reformulações e redefinições. 


\section{Referências}

Aguilar, S. L. (2008). Políticas de Defesa e Orçamentos Militares no Cone Sul. Defesa, Segurança Internacional e Forças Armadas: textos selecionados do Primeiro Encontro da Associação Brasileira de Estudos de Defesa. 1a ed. Campinas: Mercado de Letras, v. 1, p. 101-121.

Aguilar, S. L. (2011). A Participação Sul-Americana nas Operações de Paz da ONU - Algumas Considerações. Security and Defense Studies Review 12, 99-116.

Aguilar, S. L. (2012). Segurança pública e as operações de construção de paz pós-conflitos armados. Estudos sociológicos 17(33), 429-455.

Aguilar, S. L. (2013). Cooperação e Coordenação: algumas considerações sobre a América Latina e a segurança internacional. Recuperado de < http://www.encontronacional2013.abri.org.br/conteudo/ view?ID_CONTEUDO=877>

Andrade, R. de O. (2013). O voo do Falcão: Projetos militares contribuem para o aquecido setor de aeronaves não tripuladas. Pesquisa FAPESP, ed. 211, 64-69, Setembro de 2013, São Paulo. Recuperado de < http:// revistapesquisa.fapesp.br/wp-content/uploads/2013/09/064-069 Vants_211.pdf $>$

Bigatão, J. (2007). As operações de manutenção da paz das Nações Unidas no pós-Guerra Fria: o caso dos conflitos armados intra-estatais. Encontro da Associação Brasileira dos Estudantes de Defesa (ABED). Recuperado de <http://www.arqanalagoa.ufscar.br/abed/Integra/ Juliana\%20P\%20Bigatao\%.pdf >

Cavalcante, F. (2010). As origens conceituais da construção da paz das Nações Unidas. Univ. Rel. Int., Brasília, 8(2), 1-22.

Ceed [Centro de Estudios Estratégicos de Defensa del Consejo de Defensa Suramericano] (2013). Plan de Trabajo del Centro de Estudios Estratégicos de Defensa del Consejo de Defensa Suramericano 2013. Ceed-CDS. Recuperado de <http:// www.ceedcds.org.ar/Espanol/03Planes_de_Trabajo/Plan_de_Trabajo_CEED_2013.pdf >

Ceed [Centro de Estudios Estratégicos de Defensa del Consejo de Defensa Suramericano] (2012). Plan de Trabajo del Centro de Estudios Estratégicos de Defensa del Consejo de Defensa Suramericano 2012. Ceed-CDS. Recuperado de <http:// www.ceedcds.org.ar/Espanol/03Planes_de_Trabajo/Plan_de_Trabajo_CEED_2012.pdf>

Cepik, M. (2010). Segurança regional e integração na América do Sul. Segurança Internacional: Práticas, Tendências e Conceitos. São Paulo: Hucitec.

Comini, N. \& Frenkel, A. (2014). Una Unasur de baja intensidad: Modelos en pugna y desaceleración del proceso de integración en América del Sur. Nueva Sociedad 250, marzo-abril de 2014. 
Del Masso, F., Gonçalves, R. M. e Ferreira, R. M. Z. (2015). A (Re)Invenção do Estado do Século XXI: $\mathrm{O}$ Regresso ao Liberalismo como Suporte do Sistema Democrático. Revista Internacional Consinter de Direito, I, 306 e ss.

Ferreira, M. J. \& Sarti, F. (2011). Diagnóstico: Base Industrial de Defesa Brasileira. Agência Brasileira de Desenvolvimento Industrial. Recuperado de $<$ http://livroaberto.ibict. br/handle/1/550>

Freitas, G. Cooperação Militar na América do Sul: Estudo do Conselho de Defesa Sul-Americano e de seus Benefícios Estratégicos para o Brasil. Recuperado de <http://www. defesa.gov.br/arquivos/ensino_e_ pesquisa/defesa_academia/cādn/ artigos/xii_cadn/cooperacao_militar.pdf $>$

Frenkel, A. (2016). Entre promesas y realidades: La UNASUR y la creación de la Escuela Suramericana de Defensa. Relaciones Internacionales Número 31, Febrero 2016 - Mayo 2016, Grupo de Estudios de Relaciones Internacionales (GERI) UAM, Madri, Espanha.

Fuccille, A. (2014). Conselho de Defesa Sul-Americano (CDS): Balanços e Perspectivas. IX Encontro ABCP. Associação Brasileira de Ciência Política. Brasília, DF.

Fuccille, A. (2015). O Brasil e a América do Sul: (re)pensando a segurança e a defesa na região. Revista Brasileira de Estudos da Defesa, 1(1), 112-146.
Galerani, K. A. (2011). Conselho SulAmericano de Defesa: Cênese, Desenvolvimento Inicial e Desafios (2008-2010). (Dissertação de Mestrado em Relações Internacionais). Universidade Federal do Rio Grande do Sul, Instituto de Filosofia e Ciências Humanas, Programa de Pós-graduação em Relações Internacionais, Porto Alegre.

Hirst, M. (2007). La intervención sudamericana en Haití. FRIDE Comentario. Abril: 1-16. Recuperado de $<$ http://fride.org/publicacion/192/ la-intervencion-sudamericana-enhaiti>

Llenderrozas, E. (2006). Argentina, Brasil, Chile en la reconstrucción de Haití: intereses motivaciones de la participación conjunta. Latin American Studies Association. San Juan. Recuperado de <http://www.resdal.org/producciones-miembros/ art-Ilenderrozas-lasamar06.pdf>

Llenderrozas, E. (2007). Los incentivos de Argentina, Brasil y Chile para participar en la misión MINUSTAH en Haití. Su impacto en los mecanismos de cooperación en operaciones de paz. Recuperado de $<$ http://flacso.org.ar/wp-content/ uploads/2014/06/Disertacion.Elsa_. LLenderrozas.03-04.pdf>

Peña, F. (2009). La integración del espacio sudamericano. La Unasur y el Mercosur pueden complementarse? Nueva Sociedad, 219(jan.-fev.), 46-58.

Oliveira, E. R. (2009). A Estratégia Nacional de Defesa e a Reorgani- 
zação e Transformação das Forças Armadas. Revista Interesse Nacional, 2(5). Recuperado de http://interessenacional.uol.com.br/index. php/edicoes-revista/a-estrategianacional-de-defesa-e-a-reorganizacao-e-transformacao-das-forcasarmadas/

Pagliari, G. (2015). Conselho de Defesa Sul-Americano e a adoção de medidas de fortalecimento da confiança. Carta Internacional (USP), 10, 23-40.

Regueiro, L. \& Barzaga, M. (2012). UNASUR: proceso y propuesta. FEDAEPS, Quito.

Rezende, L. P. (2013): Sobe e desce! Explicando a cooperação em defesa na América do Sul. (Tese de Doutorado). Universidade Federal do Rio Grande do Sul, Programa de Pós-graduação em Ciência Política, Porto Alegre.

Saint-Pierre, H. (2009). La Defensa en la Política Exterior del Brasil: el Consejo Suramericano y la Estrategia Nacional de Defensa. Documento de Trabajo, Real Instituto Decano, Madrid.

Saint-Pierre, H. (2011). "Defesa" ou "Segurança"? Reflexões em torno de Conceitos e Ideologias. Revista Contexto Internacional, 33(2).

Saint-Pierre, H. \& Montoya, A. (2014). As medidas de confiança no Conselho de Defesa Sul-americano (CDS): análise dos gastos em Defesa (2009-2012). Revista Brasileira de Política Internacional, 57, 22-39.
Sanahuja, J. A. \& Verdes-Montenegro, F. J. (2014). Seguridad y Defensa en Suramérica: regionalismo, cooperación y autonomía en el marco de UNASUR. Em Anuario de la Integración CRIES 2013-2014. Buenos Aires: Coordinadora Regional de Investigaciones Económicas y Sociales. pp. 487-530.

Santos, S. J. (2010). Media para a paz e peacebuilding: uma crítica à intervenção internacional. Univ. Rel. Int., 8(2), 137-162.

Silva, P. F. (2011). CT\&I e Defesa Nacional: novos rumos para o debate brasileiro? Revista Brasileira de Ciência, Tecnologia e Sociedade, 2(1), 239-251.

Souza Neto, D. M. (2010). Operações de Paz e Cooperação Regional: $\mathrm{O}$ Brasil e o Envolvimento Sul-americano na Minustah. Revista da Escola de Guerra Naval, 15, 25-58.

Souza Neto, D. M. (2013). Regional defense integration and peacekeeping cooperation in the Southern Cone. Em: Kenkel (org.), South America and Peace Operations Coming of Age. $1^{\mathrm{a}}$ ed. (pp. 64-81). Londres: Routledge.

Souza, T. A. F. (2015). Cooperação em defesa e a região sul-americana: o papel do Conselho de Defesa SulAmericano, da UNASUL. (Dissertação de mestrado). Universidade Federal do Rio Grande do Sul, Programa de Pós-graduação em Estudos Estratégicos, Porto Alegre.

Torchiaro, L. (2007). Minustah: una decisión estratégica con implicaciones 
regionales. Recuperado de < http:// www.fes-seguridadregional.org/ images/stories/docs/4110-001_g. pdf $>$

Tripodi, P. \& Villar, A. (2005). Haití: la encrucijada de una intervención latinoamericana. Revista Fuerzas Armadas y Sociedad, 19(1), 17-35.

Unasul [União das Nações Sul-Americanas] (2008). Estatuto do Conselho de Defesa Sul-Americano da União de Nações Sul-Americanas. Santiago.

Unasul [União das Nações Sul-Americanas] (2009). El Consejo de Defensa Suramericano de la Unasur - Crónica de su gestación. Primera Edición, Santiago de Chile.

Unasul [União das Nações Sul-Americanas] (2010a). Confianza y Seguridad en América del Sur. Cuadernos de Defensa no. 2. Consejo de Defensa Suramericano. Quito.

Unasul [União das Nações Sul-Americanas] (2010b). Modernización de Ministerios de Defensa. Cuadernos de Defensa no. 1. Consejo de Defensa Suramericano. Quito.

Unasul [União das Nações Sul-Americanas] (2010). Plan de Acción 2010-
2011. Recuperado de <http:www. ceedcds.org.ar/Espanol/09Downloads/Esp-PA/Plan-de-Accion-2010-2011.pdf>

Unasul [União das Nações Sul-Americanas] (2012). Plan de Acción 2012. Recuperado de <http:// www.ceedcds.org.ar/Espanol/09Downloads/Esp-PA/Plan-de-Accion-2012.pdf $>$

Unasul [União das Nações Sul-Americanas] (2008). Tratado Constitutivo. Recuperado de <http://www. unasursg.org/images/descargas/DOCUMENTOS\%20CONSTITUTIVOS\%20 DE\%20UNASUR/Tratado-UNASURsolo.pdf $>$

Vales, T. P. (2013). A participação sulamericana em operações de paz: uma estratégia regional de política externa? IV Colóquio Internacional de Doutorandos/as do CES, 6-7 dezembro. Recuperado de <http:// cabodostrabalhos.ces.uc.pt/n10/ documentos/12.4.3_Tiago_Pedro_ Vales.pdf. $>$

Vilela, F. de S. (2009). Integração das indústrias de defesa na América do Sul. Revista da Escola de Guerra Naval,14, 155-172. 
